\title{
Variação na arquitetura floral e sucesso reprodutivo de duas espécies de Helicteres (Malvaceae), na região sudoeste de Mato Grosso
}

\author{
Celice Alexandre Silva ${ }^{1,2}$, Danilo Souto Ferreira ${ }^{1}$, Ana Kelly Koch ${ }^{1}$ e Lucas Eduardo Araújo-Silva ${ }^{1}$
}

Recebido em 7/09/2009. Aceito em 9/03/2010 RESUMO - (Variação na arquitetura floral e sucesso reprodutivo de duas espécies de Helicteres (Malvaceae), na região sudoeste de Mato Grosso).
Objetivou-se analisar a influência da arquitetura floral, o comportamento dos visitantes florais diurnos e a influência dos locais de deposição de pólen
no corpo dos polinizadores para o sucesso reprodutivo de Helicteres sacarolha e H. lhotzkyana. A floração de H. sacarolha ocorreu durante a estação
chuvosa (Janeiro a Abril) e de H. lhotzkyana se estendeu de Julho a Outubro (estação seca e inicio da estação chuvosa). Flores de ambas as espécies são
vistosas, zigomorfas e apresentam características de ornitofilia. Beija-flores foram os principais visitantes florais diurnos destas espécies, não tendo ha-
vido polinizadores em comum entre elas. Os beija-flores que visitaram as flores de H. sacarolha apresentaram comportamento territorialista e o local de
deposição de pólen era na cabeça ou na testa, enquanto que os que visitaram flores de $H$. lhotzkyana apresentaram comportamento "traplining" e o pólen
era depositado na cauda ou nos pés. O sucesso reprodutivo foi significativamente diferente entre as espécies, a produção média de sementes por fruto foi
de 24,56 em $H$. sacarolha e de 5,28 em $H$. lhotzkyana. As características florais e os comportamentos dos polinizadores, explicam parte das variações no
sucesso reprodutivo das espécies estudadas.

Palavras-chave: biologia reprodutiva, eficiência na polinização, morfologia floral, ornitofilia

ABSTRACT - (Variation of floral architecture and reproductive success of two Helicteres (Malvaceae) species in southwestern Mato Grosso). The aim of this study was to analyze the influence of floral architecture, the behavior of day visitors to the flowers and the influence of the location of pollen deposition on the bodies of the pollinators for the reproductive success of Helicteres sacarolha and H. lhotzkyana. Flowering of $H$. sacarolha occurred during the rainy season (January to April) and H. lhotzkyana between July and October (dry season and beginning of the rainy season). Flowers of both species are colorful and zygomorphic with characteristics of ornithophily. Hummingbirds were the main day visitors to the flowers. The species had no pollinators in common. The behavior of the hummingbirds that visited H. sacarolha flowers was territorial and the pollen was deposited on the head or forehead; the behavior of those that visited H. lhotzkyana flowers was traplining and the pollen was deposited on the tail or feet. Reproductive success was significantly different between the species; mean fruit set was 24.56 for H. sacarolha and 5.28 for H. lhotzkyana. Floral characteristics and pollinator behavior explain part of the differences in the reproductive success of the species studied.

Key words: flower morphology, ornithophily, pollination efficiency, reproductive biology

\section{Introdução}

A morfologia floral pode influenciar no acesso aos recursos florais pelos animais e a eficiência desses animais em utilizar esses recursos (Inouye 1980). Além disso, a morfologia também influencia o modo como o pólen é depositado e removido do corpo dos polinizadores e a quantidade de pólen transferido por visita (Campbell et al. 1991). Embora os locais de deposição de pólen nos corpos dos polinizadores, têm sido amplamente discutidos em diversas famílias botânicas (ver Franceschinelli 2005), poucos estudos avaliam quais são os efeitos dos diferentes locais de deposição de pólen no sucesso reprodutivo das espécies ornitófilas (Lara \& Ornelas 2001).

A evolução de plantas ornitófilas e outros polinizadores vertebrados, têm se apresentado bastante próximas (Muchhala 2007) e é razoável supor que a variação na arquitetura floral passa pela variação no sucesso reprodutivo das plantas, principalmente quando as características envolvidas afetam a atração de polinizadores ou transferência de pólen (Herrera 1990).

Caracteres florais têm sido tradicionalmente utilizados para descrever as síndromes de polinização. Flores polinizadas por beija-flores são geralmente correlacionadas a corolas vermelhas, tubulares, anteras e estigmas exertos, inodoras e com produção de grande volume de néctar diluído (Grant \& Grant 1965; Fægri \& van der Pijl 1979). Características morfológicas, ecológicas e fisiológicas das plantas estão relacionadas aos agentes polinizadores e as análises destas características auxiliam os estudos da ecologia reprodutiva (Faegri \& van der Pij1 1979). O padrão fenológico e a disponibilidade de recursos regulam a ocorrência das espécies vegetais e seus vetores de pólen em uma comunidade ao longo do ano (Koptur et al. 1988). Em regiões tropicais, muitos estudos indicam que as fenofases são correlacionadas não somente aos fatores endógenos, mas também às condições ambientais como luz, precipitação e temperatura (Morellato et al. 1989).

Helicteres L. é um gênero pantropical que compreende aproximadamente 43 espécies. No Brasil ocorrem cerca de 30 espécies presentes em várias formações vegetacionais (Barroso et al. 1978), geralmente, em agrupamentos denominados "manchas". As flores do gênero são vistosas, zigomorfas, pediceladas, geralmente pêndulas e inodoras. $\mathrm{O}$ androginóforo é longo, com 10 estames transversais exertos a uma corola de cor amarela a vermelho. As características florais dessas espécies sugerem morcegos (Sazima \& Sazima 1988) e beijaflores como seus polinizadores (Franceschinelli 2005).

Embora o gênero apresente distribuição em diferentes biomas, a biologia da polinização em espécies de Helicteres

\footnotetext{
Universidade Estadual de Mato Grosso, Centro de Pesquisas, Estudos e Desenvolvimento Agro-Ambientais (CPEDA), Laboratório de Botânica, Tangará da Serra, MT, Brasil

2 Autor para correspondência: celicealexandre645@hotmail.com
} 
em território brasileiro ainda é pouco conhecida. Foram estudadas as espécies: $H$. ovata Lam. na Reserva de Santa Genebra em Campinas - SP (Sazima \& Sazima 1988); $H$. guazumaefolia Kunth no Pantanal de Mato Grosso do Sul (Araújo \& Sazima 2003); H. mollis K. Schum e H. velutina K. Schum na Caatinga pernambucana (Machado \& Lopes 2004); H. brevispira St. Hil. e H. sacarolha St. Hill. na Estação Ecológica de Mogi Guaçu - SP (Franceschinelli 2005). Apesar da escassez de estudos, algumas espécies de Helicteres apresentam propriedades medicinais, como, por exemplo, H. sacarolha (Barroso et al. 1978) e H.isora L. (Yakandawala et al. 2006).

Apresentamos aqui um estudo comparativo de variação na arquitetura floral em duas espécies congêneres de Helicteres, com diferentes mecanismos de deposição de pólen, para responder às seguintes questões: (a) Qual é o período de floração das espécies? (b) Quais são os visitantes florais diurnos e, dentre eles, os efetivos polinizadores? (c) Há polinizadores comuns entre estas espécies? (d) Quais os comportamentos dos polinizadores? e (e) Os locais de deposição de pólen no corpo dos polinizadores influenciam na taxa de frutificação das espécies?

\section{Material e métodos}

Áreas de estudo e espécies estudadas - Os estudos foram conduzidos, durante $\mathrm{o}$ ano de 2008, em dois fragmentos florestais com fitofisionomias diferentes, localizados no município de Tangará da Serra $\left(14^{\circ} 04^{\prime} \mathrm{S}\right.$ e $\left.57^{\circ} 03^{\prime} \mathrm{W}\right)$ região sudoeste do estado de Mato Grosso. Esta região caracteriza-se climaticamente como tropical úmido megatérmico (AW), segundo a classificação de Köppen, com temperatura média anual de $24,4^{\circ} \mathrm{C}$. A precipitação média anual é de $1.500 \mathrm{~mm}$ e a umidade relativa do ar varia de $50-80 \%$ (Vela et al. 2006). A estação chuvosa estende-se de outubro a abril e a estação seca de maio a setembro. Durante o período de 2003 a 2008 observou-se que a maior média mensal de precipitação $(\bar{X}=275,23 \mathrm{~mm})$ concentrou-se nos meses de dezembro e janeiro e o período de maior seca $(\bar{X}=6,56 \mathrm{~mm})$ foi registrado nos meses de julho e agosto. Os solos da região são do tipo Areno-argilosos, distróficos ou de baixa fertilidade. Atualmente, a vegetação original encontra-se fragmentada circundada por grandes monoculturas de soja e milho. Os dados climatológicos foram fornecidos pela estação meteorológica do Instituto Nacional de Meteorologia - INMET instalada na Universidade do Estado de Mato Grosso (UNEMAT), localizada próximo às áreas de estudos.

Helicteres sacarolha foi estudada em um fragmento florestal (ca de 28 ha) de campo sujo, caracterizado pela presença de árvores baixas ( 5 a $7 \mathrm{~m}$ ), espaçadas e de aspecto xeromórfico, associadas a um tapete gramininoso contínuo dominado por espécies de Andropogon spp. e Trachypogon spp. (Veloso et al. 1991). Helicteres lhotzkyana (Schott \& Endl.) K. Schum foi estudada em um fragmento (ca de 18 ha) de floresta estacional semidecidual (IBGE 1992). Os dois fragmentos florestais estão distantes entre si por cerca de $500 \mathrm{~m}$.

Fenologia reprodutiva-A determinação das fenofases de floração e frutificação foi feita através de registros semanais em 10 indivíduos de cada espécie, durante o período de floração e frutificação. A antese foi acompanhada em botões florais de inflorescências previamente marcadas de 10 indivíduos de cada espécie. Em cada espécie estudada foi registrado: o número de inflorescência por ramo, o número de flores por inflorescência e o número de flores abertas por inflorescência/dia. Devido ao porte arbustivo-arbóreo de H. lhotzkyana, os registros fenológicos de floração foram acompanhados em três ramos por indivíduo, escolhidos aleatoriamente.

Experimentos de polinização manual em flores de $H$. sacarolha e $H$. lhotzkyana demonstraram que ambas as espécies são autoincompativeis (C.A.Silva, dados não publicados). A produção de frutos e sementes oriundos de polinizações naturais foi verificada em cinco ramos, previamente marcados, de cinco indivíduos diferentes em ambas as espécies estudadas.

Espécimes testemunhos foram coletados, identificados e depositados no Herbário Central da Universidade Federal de Mato Grosso - UFMT $\mathrm{N}^{\circ}$ s 34.822 e 38.657 .

Biologia e morfologia floral - Para o estudo da biologia floral foi observada a longevidade das flores (desde a abertura da corola e exposição dos órgãos reprodutivos até a senescência) de 10 botões de cada espécie provenientes de quatro indivíduos diferentes. A senescência foi caracterizada pela perda da receptividade do estigma além da alteração da coloração da corola (da cor amarela para a vermelha). Durante o período de antese das flores, a receptividade do estigma foi verificada usando peróxido de hidrogênio a 3\% (sensu Dafni 1992).

A análise da morfologia floral e a dinâmica de abertura das flores foi acompanhada em 20 flores (10 de cada espécie) coletadas de cinco indivíduos diferentes por espécie.

Morfometria floral - O comprimento do cálice e da corola, a mensuração do androginóforo, anteras e pistilo, foram obtidos usando paquímetro (precisão de $0,01 \mathrm{~mm}$ ) em dez flores, totalmente abertas provenientes de cinco indivíduos diferentes de cada espécie. O número de óvulos por ovário foi contado em 15 flores de cinco indivíduos diferentes de cada espécie, com auxilio de microscópio estereoscópico.

Visitantes florais - As observações dos beija-flores visitantes foram realizadas durante três dias consecutivos, durante o pico de floração das espécies, no periodo de maior atividade dos polinizadores diurnos nas áreas de estudo, ou seja, de 5:30 às 10:30 hs, totalizando 15 horas de observações por espécie. Em cada sessão de observação foi anotado o comportamento dos visitantes, o número de flores visitadas por individuo, o horário da visita e o local de deposição de pólen no corpo do visitante e quando possivel, a distinçao focal do sexo do visitante. As observações das visitas realizadas por beija-flores foram feitas com auxílio de binóculos, máquina fotográfica e guia de campo (Sigrist 2007), na nomenclatura dos beija-flores seguiu-se as orientações do Comitê Brasileiro de Registros Ornitológicos (CBRO 2008).

Para avaliar a eficiencia de possiveis polinizadores noturnos (morcegos), 28 botões, em pré antese, de dez individuos diferentes de $H$. sacarolha e 21 botões, de oito individuos diferentes de H. lhotzkyana, foram ensacados com sacos do tipo organza e acompanhadas durante toda a antese. Para tanto, nas primeiras horas do dia e durante toda a antese as flores foram ensacadas para excluir os visistantes diurnos e a noite esses sacos foram retirados e as flores disponibilizadas aos visitantes noturnos. Após sua senescência, as flores foram acompanhadas no campo até a queda das mesmas ou o desenvolvimento de frutos.

\section{Análises dos dados}

Análises estatísticas foram conduzidas usando General Linear Model, no software Statistica versão 5.5 (StatSoft, 2002). Foi utilizado o teste One - way ANOVAs para analisar as diferenças na morfometria floral, número de óvulos por ovário e o sucesso reprodutivo das espécies.

\section{Resultados}

Disponibilidade de flores e produção de frutos - O período de florescimento de $H$. sacarolha ocorreu entre janeiro a abril de 2008, durante a estação chuvosa. O pico de floração ocorreu no mês de fevereiro. O número de flores abertas por ramo variou de 11 a $24(\bar{X}=18,0 \pm 3,2 ; \mathrm{n}=10)($ Tab. 1$)$. O período de frutificação ocorreu de abril a junho de 2008.

Helicteres lhotzkyana iniciou o florescimento entre os meses de julho entendendo até outubro de 2008, durante a estação seca e inicio da estação chuvosa, com pico de floração no mês de setembro. $\mathrm{O}$ número de flores por inflorescência variou de duas a três (Tab. 1). O número de flores abertas por ramo variou de quatro a $21(\bar{X}=15,2 \pm 0,53 ; \mathrm{n}=10)$. $\mathrm{O}$ 
Tabela 1. Números médios e desvio padrão das características florais de Helicteres sacarolha St. Hill. e Helicteres lhotzkyana (Schott \& Endl.) K. Schum. (Malvaceae) $(\mathrm{n}=10)$, em fragmentos florestais de Tangará da Serra, MT, Brasil.

\begin{tabular}{|c|c|c|c|c|c|}
\hline Espécie & $\begin{array}{l}\text { Inflorescência/ramo } \\
\qquad(\bar{X} \pm D P)\end{array}$ & $\begin{array}{l}\text { Flores/inflorescência } \\
\qquad \bar{X} \pm \mathrm{DP})\end{array}$ & $\begin{array}{c}\text { Flores abertas/ } \\
\text { inflorescência/dia } \\
(\bar{X} \pm D P)\end{array}$ & $\begin{array}{l}\text { Frutos/ramo } \\
(\overline{\mathrm{X}} \pm \mathrm{DP})\end{array}$ & $\begin{array}{l}\text { Sementes/fruto } \\
\qquad(\bar{X} \pm D P)\end{array}$ \\
\hline H. sacarolha & $18,3 \pm 6,13$ & $3,61 \pm 1,47$ & $1,02 \pm 0,39$ & $10,92 \pm 6,03$ & $24,56 \pm 10,56$ \\
\hline H. lhotzkyana & $13,1 \pm 4,46$ & $2,51 \pm 0,34$ & $1,16 \pm 0,55$ & $1,24 \pm 0,72$ & $5,28 \pm 4,45$ \\
\hline
\end{tabular}

período de frutificação ocorreu durante os meses de outubro a novembro do mesmo ano e em ambas as espécies frutos imaturos e maduros ocorreram simultaneamente.

Embora H. sacarolha e H. lhotzkyana tenham produzido números similares de flores por inflorescência (3,61 vs. 2,51 respectivamente) uma proporção muito menor dessas flores formaram frutos e sementes em H. lhotzkyana (Tab. 1). O sucesso reprodutivo de $H$. sacarolha foi significativamente superior ao apresentado por $H$. lhotzkyana $(\mathrm{F}=10,47 ; \mathrm{p}=$ 0,003 ) consistente com a alta taxa de visitação apresentada na primeira espécie.

Biologia e morfologia floral - Flores de $H$. sacarolha e $H$. lhotzkyana iniciaram a antese no final da tarde e duravam cerca de três dias. Ambas as espécies apresentaram produção de néctar na base da corola nos dois primeiros dias da antese. Em flores de H. sacarolha as sépalas e as pétalas permaneceram alaranjadas durante toda a antese. No primeiro dia de antese dessa espécie as flores apresentavam uma curvatura no androginóforo, as anteras não liberaram pólen e o estigma apresentava-se receptivo. Flores de segundo dia apresentaram o androginóforo ereto, anteras deiscentes com pólen visível e receptividade no estigma. As flores do terceiro dia iniciaram a senescência ao entardecer, nesse período os estigmas não se apresentavam receptivos e as anteras apresentavam-se reflexas, escuras e sem pólen.

No primeiro dia de abertura das flores de H. lhotzkyana a corola apresentava-se amarela, reflexa e com um disco vermelho na extremidade distal do tubo floral, o androginóforo apresentava-se ereto e exerto à corola, o estigma mostrou-se receptivo, mas não havia liberação de pólen pelas anteras. Nas flores do segundo dia as pétalas apresentavam-se alaranjadas e estas obstruíam, parcialmente, a entrada do tubo da corola, nas anteras havia liberação de pólen e o estigma permanecia receptivo. Nas flores do terceiro dia a corola apresentou-se vermelha, senescente e obstruindo totalmente à entrada do tubo floral. O estigma apresentou-se receptivo, mas não havia liberação de pólen nas anteras.

Morfometria Floral - Flores de $H$. sacarolha são, geralmente, menores que as flores de H. lhotzkyana, o androginóforo é longo em ambas as espécies, porém em H. lhotzkyana ele é duas vezes maior que o de $H$. sacarolha (Tab. 2). O número de óvulos por ovário não variou significativamente $(\mathrm{F}=0,75$, $\mathrm{p}=0,99)$ entre as espécies $(\bar{X}=63,33 \pm 3,62, \mathrm{n}=15 \mathrm{em} H$. sacarolha e $\bar{X}=74,26 \pm 1,22, \mathrm{n}=15 \mathrm{em}$ H. lhotzkyana).

Visitantes florais - Quatro espécies de beija-flores da família Trochilidae foram registradas visitando flores de $\mathrm{H}$. sacaro- lha e H. lhotzkyana (Tab. 3). Não houve polinizadores em comum entre as espécies. Um beija - flor podia visitar três a 49 flores por individuo/dia em $H$. sacarolha e duas a 34 flores em $H$. lhotzkyana.

Das 483 visitas registradas em $H$. sacarolha, 473 foram feitas por indivíduos de Anthracothorax nigricollis (Vieillot 1817) seguido por Polytmus guainumbi (Pallas 1764) (Tab.3). Média de 41,16 $\pm 12,63$ visitas flor ${ }^{-1} \mathrm{~h}^{-1}$. As flores dessa espécie não apresentavam variações de cores na corola e todas as flores abertas por planta eram visitadas. Indivíduos de $A$. nigricollis apresentaram comportamento territorialista, expulsando até mesmo a fêmea de sua espécie, permanecendo constantemente em sentinela próximo às plantas de $H$. sacarolha principalmente, no inicio da manhã (6:00 às 8:00 hs). Todos os beija-flores foram observados com pólen depositado na cabeça (Fig.1).

Helicteres lhotzkyana foi visitada por indivíduos de Phaethornis pretrei (Lesson \& Dellattre 1839) e Thalurania furcata (Gmelin 1788). Essas espécies visitavam esporadicamente as flores de $H$. lhotzkyana e em $92 \%$ das vezes, essas visitas eram em flores amarelas (primeiro dia). As espécies apresentavam comportamento de "traplining" (sensu Linhart 1973) e retornavam às flores em intervalos de 1:00 à 1:30 h. Baseado na morfologia floral e confirmado em observações em campo, essas espécies recebiam o pólen na cauda ou nos pés (Fig. 1). Em 15 horas de observação nós registramos em média 20,00 $\pm 28,26$ visitas flor ${ }^{-1} \mathrm{~h}^{-1}$. Os experimentos mostraram que existem polinizadores noturnos em $\mathrm{H}$. sacarolha, onde $32,1 \%$ dos botões florais marcados produziram frutos. Por outro lado, em $H$. lhotzkyana, nenhum dos botões florais marcados e expostos à visitação noturna resultou em frutificação.

\section{Discussão}

Embora as populações estudadas estejam espacialmente próximas (ca. de 500m) não houve sobreposição no período de floração das espécies, evitando assim, a competição por polinizadores entre elas.

Helicteres sacarolha floresceu e frutificou durante a estação chuvosa e em H. lhotzkyana a disponibilidade hídrica parece também influenciar, pois o pico de floração ocorreu no final da estação seca e a floração foi intensificada com a ocorrência de chuvas ocasionais (obs. pess.). Em cerrado aberto no estado de São Paulo, Franceschinelli (2005) observou que $H$. sacarolha também apresentou um período de floração de quatro meses, (de dezembro a março) com o pico 
Tabela 2. Médias e desvio padrão (variação entre parênteses) de flores de Helicteres sacarolha St. Hill. e Helicteres lhotzkyana (Schott \& Endl.) K. Schum. (Malvaceae) $(\mathrm{n}=10)$, em fragmentos florestais de Tangará da Serra, MT, Brasil.

\begin{tabular}{lccccc}
\hline & Cálice $(\mathrm{cm})$ & Corola $(\mathrm{cm})$ & Androginóforo $(\mathrm{cm})$ & Antera $(\mathrm{cm})$ & Pistilo $(\mathrm{cm})$ \\
\hline H. sacarolha & $2,12 \pm 0,18(2,0-2,6)$ & $1,72 \pm 0,09(1,6-1,8)$ & $3,27 \pm 0,12(3,0-3,4)$ & $0,14 \pm 0,03(0,1-0,15)$ & $0,81 \pm 0,03(0,8-0,9)$ \\
H. Ihotzkyana & $1,74 \pm 0,12(1,5-1,9)$ & $2,9 \pm 0,31(2,4-3,4)$ & $7,45 \pm 0,55(6,2-8,2)$ & $0,17 \pm 0,04(0,1-0,2)$ & $0,74 \pm 0,05(0,7-0,8)$ \\
\hline
\end{tabular}

Tabela 3. Porcentagem de visitação (número de visitas) em flores de Helicteres sacarolha St. Hill. e Helicteres lhotzkyana (Schott \& Endl.) K. Schum. (Malvaceae), em fragmentos florestais de Tangará da Serra, MT, Brasil.

\begin{tabular}{lcc}
\hline Visitantes & \multicolumn{2}{c}{ Porcentagem de visitação } \\
& Helicteres sacarolha & Helicteres lhotzkyana \\
\hline Anthracothorax nigricollis $\hat{0}$ & $82,18(406)$ & - \\
Anthracothorax nigricollis + + & $13,56(67)$ & - \\
Polytmus guainumbi $\widehat{\gamma}$ & $2,07(10)$ & - \\
Phaethornis pretrei & - & $62,33(48)$ \\
Thalurania furcata $\hat{\text { o }}$ & - & $18,18(14)$ \\
\hline
\end{tabular}

em janeiro. Segundo essa autora, o período de receptividade das flores foi de apenas um dia. Essas diferenças quanto ao inicio de floração e o tempo de duração das flores de mesma espécie em áreas diferentes indica que fatores ambientais são mais importantes para a fenologia destas espécies que fatores intrínsecos como, relações filogenéticas e história evolutiva do grupo (Kochmer \& Handel 1986).

A predominância de visitas de beija-flores troquilíneos às flores de H. sacarolha foi esperada, pois as espécies dessa sub-familia forrageiam, preferencialmente, em locais mais abertos (Piratelli 1997; Machado \& Semir 2006). Já a ocorrência de H. lhotzkyana no interior de mata possibilitou as visitas de Phaethornis pretrei, que forrageia, preferencialmente, em ambientes sombreados (Piratelli 1997). A baixa freqüência de Thalurania furcata observada nesse estudo também foi constatada apenas no período de cheia do Pantanal matogrossense e pode estar associada a deslocamentos em busca de florações sazonais (Nunes \& Tomas 2008).

A disponibilidade de polinizadores diurnos e noturnos sugere a possibilidade de doação e recebimento de pólen 24 horas por dia, aumentando assim o sucesso reprodutivo da espécie (Jennersten 1988). Os resultados dos experimentos de exclusão de polinizadores diurnos indicam que a polinização de $H$. sacarolha, na área de estudo é predominantemente diurna. Embora não tenha sido possível quantificar a produção de néctar durante a antese das flores, o fato de ambas as espécies começarem produção no final de tarde, sugere que visitantes noturnos seriam os primeiros a explorá-lo. O maior número de visitas de beija-flores em $H$. sacarolha ocorreu antes das 8:00 hs e em H. lhotzkyana antes das 07:30hs. Esses resultados demonstram que os beija-flores forrageiam oportunisticamente o néctar produzido durante a noite. Em estudos de padrões de comunidades de vertebrados nectarívoros, Fleming et al. (2005) registraram que no Brasil, os beija-flores visitam predominantemente ervas, trepadeiras, epífitas e arbustos, enquanto que os morcegos visitam flores de epífitas de dossel e árvores. Logo, a ocorrência de $H$. lhotzkyana no interior da mata, pode ter limitado a atuação dos visitantes noturnos, pela dificuldade de movimentação por entre os ramos.

A morfometria do cálice e da corola das espécies de Helicteres aqui estudadas foi semelhante e por isso, fatores como tamanho de bico e asas não foi determinante para a exploração dessas flores.

Três fatores podem ser apontados como responsáveis pelo baixo sucesso reprodutivo de H. lhotzkyana: a baixa taxa de visitação, a mudança de cor e posição das pétalas e o local de deposição do pólen no corpo do polinizador.

Devido à baixa frequencia de visitação, os beija-flores Phaethornis pretrei $\mathrm{e}$ Thalurania furcata foram considerados polinizadores esporádicos de H. lhotzkyana. Ambos apresentavam estratégia de forrageamento do tipo "traplining", i.e., aves que repetem o circuito de forrageamento entre sucessivas flores ou agrupamentos florais (Linhart 1973). Apesar de esse comportamento favorecer a polinização cruzada (cf. Stiles 1975), a baixa freqüência de visitação (Tab. 3) aliada ao compartilhamento de polinizadores com outras espécies ornitófilas como, por exemplo, Pyrostegia venusta (Bignoniaceae) resultou em um baixo sucesso reprodutivo individual. Por outro lado, beija-flores com alta demanda energética e que utilizam estratégia "traplinner", forrageiam em extensas rotas de capturas e visitam flores de diversas populações, favorecendo o fluxo gênico entre elas (Feinsinger \& Colwell 1978).

Embora a mudança de coloração de amarelo a um laranja-avermelhado esteja dentro do padrão de coloração de espécies ornitófilas, em flores de H. lhotzkyana essa mudança de coloração pode ser interpretado como um sinal a longa distância, relacionada a um declínio na produção de néctar e final da antese, apesar das flores ainda apresentarem-se 

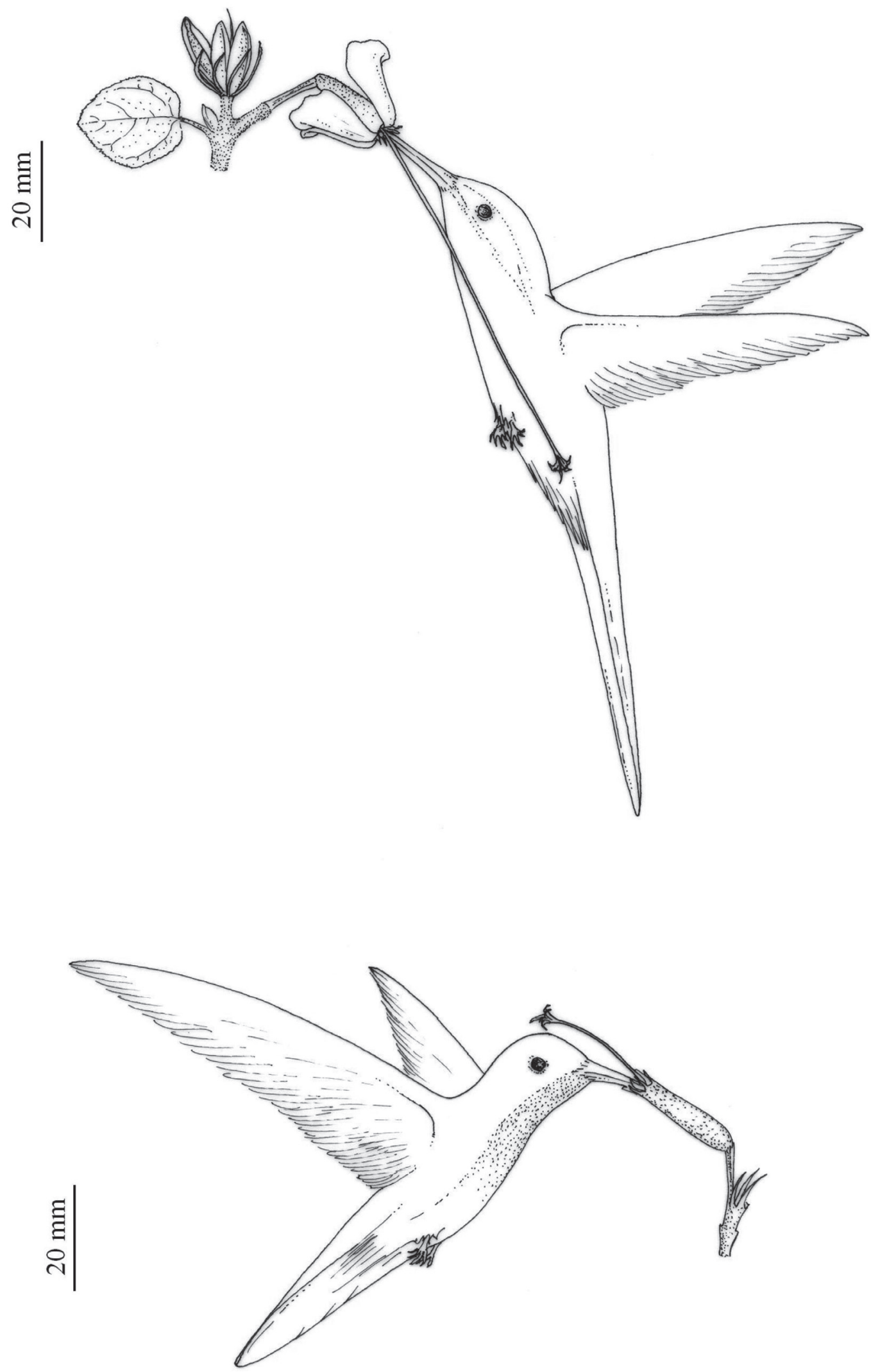

Figura 1. Locais de deposição de pólen no corpo de polinizadores de Helicteres (Malvaceae) : H. lhotzkyana (Schott \& Endl.) K. Schum depositando pólen nos pés ou rabo (acima). H. sacarolha St. Hill., depositando pólen na cabeça ou testa (abaixo), observados em fragmentos florestais de Tangará da Serra, MT, Brasil. 
funcionais. Os beija-flores são sensíveis às mudanças de cor de algumas espécies (Gottsberger \& Silberbauer-Gottsberger 1988; Meléndez-Ackerman et al. 1997) e essa mudança de coloração das pétalas, geralmente serve para anunciar ao polinizador a associação entre a qualidade e a disponibilidade do recurso floral (Meléndez-Ackerman et al. 1997).

A preferência de visitas às flores amarelas de $H$. brevispira ao longo de todo o dia também foi relacionado a uma maior produção de néctar (Franceschinelli 2005).

A morfometria do androginóforo das espécies de Helicteres levam os beija-flores a receberem a deposição do pólen em diferentes locais do corpo e pode influenciar no sucesso reprodutivo dessas espécies. Embora ambas as espécies apresentem produção semelhante de óvulos por ovário, a produção de frutos em $H$. sacarolha foi 10 vezes maior que a de $H$. lhotzkyana. Na primeira espécie as flores não são pêndulas, mas eretas e os beija-flores receberam o pólen, durante a visita na cabeça ou na testa. Em H. lhotzkyana, devido à posição peculiar de suas flores a deposição do pólen foi na cauda ou pés do beija-flor, dependendo do tamanho do mesmo. A deposição dos grãos de pólen na testa parece ser mais eficiente que a deposição na cauda, pois dificulta a perda de parte desses grãos durante o vôo, ou pelos movimentos de limpeza do corpo do beija-flor (Sick 1985).

Deposição de pólen em diferentes locais do corpo do polinizador tem sido registrada em espécies de Helicteres: em $H$. sacarolha e $H$. brevispera foi depositado na testa e abdômen, respectivamente (Franceschinelli 2005), e em flores de $H$. ovata a deposição foi em asas de morcegos (Sazima \& Sazima 1988). Segundo Lara \& Ornelas (2001) características florais como o comprimento da corola, a curvatura e o ângulo da flor em relação ao polinizador, variam consideravelmente entre plantas polinizadas por beija-flores e afetam a eficiência de forrageamento dessas aves.

Nossos resultados demonstram que os polinizadores e seus comportamentos foram marcadamente diferentes em ambas as espécies. A arquitetura floral das espécies estudadas leva a uma deposição de pólen em diferentes locais do corpo dos beija-flores e explicam, em parte, as variações no sucesso reprodutivo dessas espécies.

\section{Agradecimentos}

Os autores agradecem a Rosilene Rodrigues (Herbário Central da UFMT) pela identificação das espécies, ao Prof. Rivanildo Dallacort (Unemat) pela disponibilização dos dados climatológicos e aos dois revisores anônimos pelos comentários valiosos na primeira versão do manuscrito.

\section{Referências bibliográficas}

Araújo, A.C. \& Sazima, M. 2003. The assemblage of flowers visited by hummingbirds in the "capões" of Southern Pantanal, Mato Grosso do Sul, Brazil. Flora 198: 427-435.

Barroso, G.M.; Peixoto, A.L.; Costa, C.G.; Ichaso, C.L.F.; Guimarães, F. \& Lima, H.C.1978. Sistemática de Angiospermas no Brasil. Viçosa, Editora UFV.

Campbell, D.R.; Waser,N.M.; Price, M.V.; Lynch, E.A. \& Mitchell, R.J. 1991. Components of phenotypic selection: pollen export and flower corolla width in Ipomopsis aggregata. Evolution 45:1458-1467.
Comitê Brasileiro de Registros Ornitológicos (CBRO). 2008. Listas das aves do Brasil. Versão 05/10/2008. Disponível em http://www.cbro. org.br. Acesso em 23/03/2009.

Dafni, A.1992. Pollination ecology - a practical approach. Oxford, Oxford University.

Fægri, K. \& van der Pijl, L. 1979. Principles of pollination ecology. 3 ed. London, Pergamon Press.

Feinsinger, P. \& Colwell, R. 1978. Community organization among neotropical nectar-feeding birds. American Zoologist 18:779-795.

Fleming, T.H., Muchhala, N. \& Ornelas, J.F. 2005. New world nectarfeeding vertebrates:Community patterns and processes. Pp.163-186. In: Contribuciones mastozoológicas en homenaje a Bernardo Villa. México. Conabio.

Franceschinelli, E.V. 2005. The pollination biology of two species of Helicteres (Malvaceae) with different mechanisms of pollen deposition. Flora 200: 65-73.

Gottsberger, G. \& Silberbauer-Gottsberger, I. 1988. Evolution of flower structures and pollination in Neotropical Cassiinae (Caesalpiniaceae) species. Phyton 28:293-320.

Grant, K. A. \& Grant, V. 1965. Hummingbirds and their flowers. New York, Columbia University Press.

Herrera, C.M. 1990. The adaptedness of the floral phenotype in a relict endemic, hawkmoth-pollinated violet. 2. Patterns of variation among disjunct populations. Biological Journal of the Linnean Society 40:275-291.

Inouye,D.W. 1980.The effect of proboscis and corolla tube lengths on patterns and rates of flower visitation by bumblebees. Oecologia 45: 197-201.

Instituto Brasileiro de Geografia e Estatística - IBGE 1992. Manuais Técnicos em Geociências. Manual técnico da vegetação brasileira. Rio de Janeiro, IBGE.

Jennersten, O. 1988. Pollination of Viscaria vulgaris (Caryophylaceae): the contribution of diurnal and nocturnal insects to seed set and seed predation. Oikos 52: 319-327.

Koptur,S., Haber, W.A., Frankie,G.W.\& Baker, H.G. 1988. Phenological studies of shrub and treelet species in tropical cloud forest of Costa Rica. Journal of Tropical Ecology 4: 323-346.

Kochmer, J.P. \& Handel, S. N. 1986. Constraints and competition in the evolution of flowering phenology. Ecological Monographs 56: 303-325.

Lara, C.\& Ornelas, J.F. 2001. Preferential néctar robbing of flowers with long corollas: experimental studies of two hummingbird species three plant species. Oecologia 128: 263-273.

Linhart, Y.B. 1973. Ecological and behavioral determinants of pollen dispersal in hummingbirds-pollinated Heliconia American Naturalist 107: 511-523.

Machado I.C. \& Lopes A. V. 2004. Floral traits and pollination systems in the Caatinga, a brazilian tropical dry forest. Annals of Botany 94: 365-376.

Machado, C.G. \& Semir, J. 2006. Fenologia da floração e biologia floral de bromélias ornitófilas de uma área da Mata Atlântica do sudeste brasileiro. Revista Brasileira de Botânica 29: 163-174.

Meléndez-Ackermam, E., Campbel, D.R. \& Waser, N.M. 1997. Hummingbird behavior and mechanisms of selection on flower color in Ipomopsis. Ecology 78: 2532-2541.

Morellato, L.P.C., Rodrigues, R.R., Leitão-Filho, H.F. \& Joly, C.A. 1989. Estudo comparativo da fenologia de espécies arbóreas de floresta de altitude e floresta mesófila semi-decídua na Serra do Japí, Jundiaí, São Paulo. Revista Brasileira de Botânica 12: 85-98.

Muchhala, N. 2007. Adaptative trade-off in floral morphology mediates specialization for flowers pollinated by bats and hummingbirds. The American Naturalist 169: 494-504.

Nunes, A.P. \& Tomas, W.M. 2008. Aves migratórias e nômades ocorrentes no Pantanal. Corumbá: Embrapa Pantanal.

Piratelli, A.J.1997. Comportamento alimentar de beija-flores em duas espécies de Hippeastrum Herb. (Amaryllidaceae). Revista Brasileira de Biologia 57: 261-273.

Sazima, M.\& Sazima, I. 1988. Helicteres ovata (Sterculiaceae). Pollinated by bats in souttheastern Brasil. Botânica Acta 43: 269 - 271.

Sick, H. 1985. Ornitologia brasileira, uma introdução. Brasilia, Ed. Universidade de Brasilia.

Sigrist, T. 2007. Aves do Brasil Oriental. São Paulo, Avis Brasilis (Série Guias de Campo). 
Statsoft, Inc. 2002. Statistica for windows (Computer Program Manual). Tulsa, StatSoft INC.

Stiles, F.G. 1975. Ecology, flowering phenology, and humming birds pollination of some Costa Rica Heliconia species. Ecology 56: 285-301.

Vela, R.H.N., Dallacort, R. \& Nied, A.H. 2006. Distribuição descendial, mensais e totais de precipitação na região de Tangará da Serra - MT.
In: Anais do XXXVI Congresso Brasileiro de Engenharia Agrícola. Bonito - MS 2006. Mato Grosso do Sul.

Veloso, H.P., Rangel-Filho, A.R.; Lima, J.C.A. 1991. Classificação da vegetação brasileira, adaptada a um sistema universal. IBGE, Rio de Janeiro.

Yakandawala, K.; Wijesundara, D.S.A.; Jayasekera, S.J.B.A.\& Thirimanne, T.L.S. 2006. Ethnobotany of Helicteres isora The Nature of Success: Success for Nature 20: 1-3.

Versão eletrônica do artigo em www.scielo.br/abb e http://www.botanica.org.br/acta/ojs 